\title{
Consumption, earnings risk, and payout ratios
}

\section{Claude Bergeron*}

École des sciences de l'administration (ESA), Université du Québec (TÉLUQ), Québec, Québec, Canada

Email: claude.bergeron@teluq.ca

*Corresponding author

\section{Jean-Pierre Gueyie and Komlan Sedzro}

École des sciences de la gestion (ESG), Université du Québec à Montréal (UQÀM), Montréal, Québec, Canada

Email: gueyie.jean-pierre@uqam.ca

Email: sedzro.k@uqam.ca

\begin{abstract}
This paper investigates the theoretical relationship between earnings, risks and dividends, in an intertemporal context. After assuming that firms adjust their dividend payments toward a target dividend payout ratio, we utilize the framework of the consumption capital asset pricing model (CCAPM) to examine the effect of systematic earnings risk on dividend policy. Our main result indicates that the dividend payout ratio of a firm is negatively related to its earnings consumption beta, obtained from the covariance between aggregate consumption and earnings. This result suggests that risk measured with earnings influences dividend policy. This result also suggests that the earnings consumption beta integrates the multiple dimensions of a firm's earnings risk.
\end{abstract}

Keywords: Dividend policy; Earnings beta; Intertemporal model; Consumption risk; CCAPM.

Reference to this paper should be made as follows: Bergeron, C., Gueyie, J-P. and Sedzro, K. (201X) 'Consumption, earnings risk, and payout ratios', American J. Finance and Accounting, Vol. XX No. X, pp. XX-XX.

Biographical notes: Claude Bergeron, $\mathrm{PhD}$, is an Associate Professor of Finance at the University of Quebec (TÉLUQ), Canada. His research interests are in dividend policy, stock valuation, and intertemporal models. He has published research papers in international peer-reviewed journals such as Journal of Economics and Finance (Springer), Finance Research Letters (Elsevier), Economics Bulletin, Journal of Theoretical Accounting Research, American Journal of Finance and Accounting, and International Journal of Economics and Finance. Dr Bergeron is the corresponding author and can be contacted at: claude.bergeron@teluq.ca 
Jean-Pierre Gueyie, $\mathrm{PhD}$, is an Associate Professor at the School of Management, University of Quebec in Montreal. He received his Ph.D. from Laval University, Canada. He has published several papers in refereed scientific journals.

Komlan Sedzro, PhD, is a Professor at the School of Management of University of Quebec in Montreal (ESG-UQAM). Professor Sedzro has a broad range of research interests encompassing such areas as governance and performance evaluation of financial and microcredit institutions, corporate finance, optimal portfolio allocation, alternative investments including hedge funds, real estate and commodity derivatives, and the application of operational research methods in finance. He has published numerous articles and given presentations at various international conferences on these topics.

\section{Introduction}

According to Baker and Weigand (2015), dividend policy remains an important topic in modern finance. Dividend policy refers to the dividend distribution policy that a firm follows in determining the size and pattern of distributions to shareholders. Firms distribute cash to shareholders through cash dividends or share repurchases. In the case of a special dividend, a firm will normally indicate that this will be a onetime large payment.

In his classic paper, Lintner (1956) demonstrates how managers determine their firm's dividend policy. His empirical model indicates that changes in dividends only partially reflect changes in earnings. He concludes that corporations seem to increase dividends only after they are reasonably certain that they will be able to maintain them permanently. In another classic paper, Gordon (1959) suggests that dividend cash flows are associated with lower risk. He asserts that paying higher dividends increases firm value because dividends payments represent a sure income, while capital gain is uncertain. Miller and Modigliani (1961) take a contrary point of view. For Miller and Modigliani (MM), in a perfect and efficient capital markets, dividend policy is irrelevant to share value, because different payout policies constitute nothing more than slicing a fixed pie of cash flows into different pieces. Changing the form of the cash distribution has no effect on a firm's value.

Following the classic studies of Lintner, Gordon and MM, many other dividend models have been proposed. For example, Black (1976) argues that paying dividend reduces firm value when considering the tax disadvantage of dividends. On the other hand, in a world with market imperfections and asymmetric information, Bhattacharya (1979) suggests that the signaling benefit from paying dividends may be traded off against the tax disadvantages in order to achieve optimal dividend policy. Also, in a world with market imperfections, Jensen (1986) proposes that 
paying dividends provides a mechanism for reducing agency costs by reducing the free cash flows available for unproductive spending.

The literature also provides interesting observations on the link between dividend payment and risk. Indeed, several empirical studies conclude that the dividend payout ratio (dividends divided by earnings) or the dividend yield (dividends divided by price) is lower for high-risk firms. ${ }^{1}$ Along this line, many models suggest that risk influences dividend payments. Examples include, Bajaj and Vijh (1990), Michaely et al. (1995), Jagannathan et al. (2000), Grullon et al. (2002), Carter (2008), Hussainey et al. (2011), Bergeron et al. (2015), and Varela (2015). According to Abdoh and Varela (2017, p. 503), "Dividends are negatively related with risk because firms that operate under high uncertainty would prefer to accumulate retained earnings by reducing dividends."

In this paper, we develop a theoretical model on the relationship between systematic earnings risk and dividend policy, in an intertemporal context.

The concept of earnings beta as a measure of systematic risk represents another important research area in accounting (or finance). For example, Beaver et al. (1970) reveal a significant positive correlation between standard market betas and accounting betas. ${ }^{2}$ Beaver and Manegold (1975), and Ismail and Kim (1989) confirm prior findings about the significant relationship between market betas and earnings betas, using a variety of accounting return variables. Karels and Sackley (1993) find a similar relationship in the U.S. banking industry. Baginski and Wahlen (2003) show that accounting betas are significantly related to the priced risk premiums in univariate regressions. Nekrasov and Shroff (2009) derive a simple risk adjustment that corresponds to the covariance between a firm's return on book equity (ROE) and economy-wide risk factors.

In an influential paper, Da (2009) proposes a novel way to estimate systematic risk, using, exclusively, accounting earnings and aggregate consumption data. More specifically, Da's model indicates that the covariance between accounting returns and aggregate consumption represents an appropriate measure of risk. His empirical results show that this measure of risk explains $58 \%$ of the cross-sectional variation in risk premia. Moreover, if we add a duration measure, the model explains more than $80 \%$ of this variation. In the same vein, Da and Warachka (2009) develop an analyst earnings beta that measures the covariance between the cash flow innovation of an asset and those of the market. They show that this cash flow risk measure is priced in the cross-section of expected stock returns. As Goyal (2012, p. 29) notes, Da's model is very useful in explaining returns. Also, as Ball and Sadka (2015, p. 51) mention, "In sum, while the empirical evidence to date is scant, these studies suggest that studying systematic earnings risk is a promising avenue for further research." In line 
with this suggestion, Bergeron et al. (2018) demonstrate that the covariance between earnings and aggregate consumption affects the intrinsic value of a firm.

Nevertheless, none of these above-mentioned works develop a theoretical model on the relationship between systematic earnings risk and dividend policy.

In this regard, the motivation for the present paper comes from the following observations: (1) the importance of dividend policy in finance; (2) the large number of studies on the negative relationship between risk and dividends; (3) the importance of earnings beta (as a measure of systematic risk) in accounting research; and (4) the absence of a theoretical model on the relationship between systematic earnings risk and dividend policy.

Our model development involves the following steps. First, we assume that dividend payments are directly and stochastically related to earnings. Second, we suppose that the intertemporal equilibrium framework of the consumption capital asset pricing model (CCAPM) represents a fundamental description of the economy. Third, we express the equilibrium expected dividend growth of a stock as a function of its dividends-consumption covariance. Fourth, we integrate the target dividend payout ratio into the last equilibrium condition. Finally, we relate the target dividend payout ratio to earnings risks.

Our main result shows that the target dividend payout ratio of a firm is negatively related to its earnings consumption beta, obtained from the covariance between aggregate consumption and earnings. The relation indicates that the payout ratio of a particular firm is $100 \%$ when the earnings consumption beta equals zero, corresponds to the aggregate payout ratio if the earnings consumption beta equals one, and tends to zero when the measure of risk tends to infinity.

Thus, the main theoretical contribution of this paper is to demonstrate that systematic earnings risk influences dividend policy. This paper also suggests that the earnings consumption beta integrates the multiple dimensions of earnings risk (for dividend decisions). Moreover, it supports the existence of an optimal dividend policy, in an intertemporal context.

The present paper can be viewed as a direct extension of Bergeron et al. (2015) and Bergeron et al. (2018). The first paper examines the theoretical relationship between the multidimensionality of risk and dividend policy, in an intertemporal context. The second paper explores the effect of earnings systematic risks on intrinsic stock values, in the same intertemporal context. The present paper combines the two previous ones and examines the theoretical relationship between earnings systematic risk and dividend policy. 
The remainder of this paper is organised as follows. Section 2 presents the dividends-earnings process. Section 3 describes the intertemporal equilibrium framework. Section 4 relates target dividend payout ratios to earnings risks. Section 5 concludes.

\section{The dividends-earnings process}

Following Bakshi and Chen (2005), Dong and Hirshleifer (2005), and Bergeron et al. (2015, p. 179), our dividend model focuses on earnings and begins by assuming that, given the available information at time $t$, dividends relate to earnings according to:

$$
\tilde{D}_{i, t+1}=d_{i t} \tilde{X}_{i, t+1}+\widetilde{\varepsilon}_{i, t+1}
$$

with

$$
E_{t}\left[\widetilde{\varepsilon}_{i, t+1}\right]=\operatorname{COV}_{t}\left[\widetilde{\varepsilon}_{i, t+1}, \bullet\right]=0,
$$

where $\tilde{D}_{i, t+1}$ is the dividends of stock $i$, at time $t+1, \tilde{X}_{i, t+1}$ is the earnings of stock $i$, at time $t+1, \widetilde{\varepsilon}_{i, t+1}$ is the usual residual random term for stock $i$ at time $t+1$, and $d_{i t}$ is the dividend payout ratio of stock $i$ at time $t\left(d_{i t}=D_{i t} / X_{i t}\right){ }^{3}$

Notice that the second line of equation (1a) simply assumes that the residual random term presents an expected value of zero, and a zero correlation with any other variables. At the aggregate level, for the entire market, we can also assume that:

$$
\tilde{D}_{m, t+1}=d_{m t} \tilde{X}_{m, t+1}+\widetilde{\varepsilon}_{m, t+1},
$$

with

$$
E_{t}\left[\tilde{\varepsilon}_{m, t+1}\right]=\operatorname{COV}{ }_{t}\left[\tilde{\varepsilon}_{m, t+1}, \bullet\right]=0
$$

where the index $m$ indicates the market. Taking the expectation on each side of equation (1) allows us to release the usual random term, to show that for a particular firm:

$$
E_{t}\left[\tilde{D}_{i, t+1}\right]=d_{i t} E_{t}\left[\tilde{X}_{i, t+1}\right]
$$

or, for the entire market:

$$
E_{t}\left[\tilde{D}_{m, t+1}\right]=d_{m t} E_{t}\left[\tilde{X}_{m, t+1}\right]
$$


which indicates that expected dividends are directly proportional to the corresponding expected earnings (for a firm or the market).

As noted by Dong and Hirshleifer (2005), this dividends-earnings process is inspired by the classic study of Lintner (1956). It assumes that firms adjust their dividend payments toward a target dividend payout ratio. In other words, it indicates that the dividends-earnings ratio of a firm is stationary, or, more precisely, it indicates that, given the available information at time $t$, the expected dividends of a firm, divided by the corresponding expected earnings, equals the current dividends of the firm, divided by the corresponding current earnings. Our goal, in the present paper, is to find the theoretical value of the above target ratio $d_{i t}$, using a fundamental economic framework.

\section{The equilibrium economic framework}

In this section, we introduce the equilibrium economic framework proposed by the CCAPM of Rubinstein (1976), Lucas (1978), and Breeden (1979). We begin by establishing that the equilibrium price of a stock corresponds to all future cash flows (dividends), where the discount factor is stochastic. Then, assuming a constant growth evolution for dividends or consumption, we demonstrate that the random future price of a stock is directly and stochastically related to its next dividend payment. Thereafter, we find the equilibrium dividend growth rate of a stock, to reveal that dividend growth rates are related to dividends-consumption covariance.

\subsection{Equilibrium price}

Following Bergeron et al. (2018, p. 154), and others before, ${ }^{4}$ our intertemporal equilibrium framework considers a hypothetical economy, in which the representative investor maximises the time-separable utility function:

$$
E_{t} \sum_{s=0}^{\infty} \delta^{s} U\left(\tilde{C}_{t+s}\right)
$$

subject to resource constraints, where $\tilde{C}_{t+s}$ is the aggregate consumption at time $t+s$ $(s=0,1,2, \ldots, \infty), U(\bullet)$ is an increasing concave and derivable function, and $\delta$ is the time discount factor $(0<\delta<1)$.

The solution to this problem, given by the first order necessary conditions, can be used to show that the equilibrium price of stock $i$, at time $t, P_{i t}$, equals: 


$$
P_{i t}=E_{t} \sum_{s=1}^{\infty} \delta^{s} \frac{U^{\prime}\left(\tilde{C}_{t+s}\right)}{U^{\prime}\left(C_{t}\right)} \tilde{D}_{i, t+s} \text {, }
$$

where $\tilde{D}_{i, t+s}$ is the dividends of stock $i$ at time $t+s \quad(s=1,2, \ldots, \infty)$, noting that premium represents a derivative of a function. ${ }^{5}$

The right-hand side of equation (4) corresponds to the present value of all future cash flows (dividends), where the stochastic discount factor, between $t$ and $t+s$, is equivalent to: $\delta^{s} U^{\prime}\left(\widetilde{C}_{t+s}\right) / U^{\prime}\left(C_{t}\right)$.

If we assume, like Bansal and Kiku (2011), and many others before, that $U(\bullet)$ corresponds to the usual power utility function, then, it is easy to prove that:

$$
P_{i t}=E_{t} \sum_{s=1}^{\infty} \delta^{s}\left(\frac{\tilde{C}_{t+s}}{C_{t}}\right)^{-\alpha} \tilde{D}_{i, t+s}
$$

where $\alpha$ represents the constant relative risk aversion parameter $(\alpha>0){ }^{6}$ Also, if we assume that the sequence of the dividend growth rates is independent and identically distributed (i.i.d.), just as the sequence of the aggregate consumption growth rates is, then we can write:

$$
\tilde{D}_{i, t+s}=D_{i t}\left(1+\tilde{g}_{i}\right)^{s}, \text { and } \quad \tilde{C}_{t+s}=C_{t}(1+\tilde{g})^{s} \text {, }
$$

where $\tilde{g}_{i}$ represents the constant dividend growth rate of stock $i$, and $\tilde{g}$ represents the constant consumption growth rate. This allows us to simplify the expression of a long-lived asset as follows:

$$
P_{i t}=E_{t} \sum_{s=1}^{\infty} \delta^{s}(1+\tilde{g})^{-s \alpha} D_{i t}\left(1+\tilde{g}_{i}\right)^{s}
$$

Since the current dividend payment of a stock is known with the available information, it can thus be passed through the conditional expectation operator as shown below:

$$
P_{i t}=D_{i t} E_{t} \sum_{s=1}^{\infty} \delta^{s}(1+\tilde{g})^{-s \alpha}\left(1+\tilde{g}_{i}\right)^{s} .
$$


or, using a compact expression:

$$
P_{i t}=D_{i t} \mu_{i t}
$$

with $\mu_{i t} \equiv E_{t} \sum_{s=1}^{\infty} \delta^{s}(1+\tilde{g})^{-s \alpha}\left(1+\tilde{g}_{i}\right)^{s}$.

Up until this point, our model development starts the economy at time $t$, but we can also start the economy at time $t+1$. In so doing, the link between the current equilibrium price of stock $i$, at time $t+1, P_{i, t+1}$, and the current dividends of stock $i$, at time $t+1, D_{i, t+1}$, can be represented this way:

$$
P_{i, t+1}=D_{i, t+1} \mu_{i, t+1}
$$

with $\mu_{i, t+1} \equiv E_{t+1} \sum_{s=1}^{\infty} \delta^{s}(1+\tilde{g})^{-s \alpha}\left(1+\tilde{g}_{i}\right)^{s} .7$

Because the variables $\tilde{g}$ and $\tilde{g}_{i}$ are i.i.d., then the mathematical expectation $\mu_{i t}$ equals the corresponding value $\mu_{i, t+1}$. Given the available information at time $t+1$, we, thus, can establish that:

$$
P_{i, t+1}=D_{i, t+1} \mu_{i t}
$$

On the other hand, given the available information in time $t$, the last equation now suggests that:

$$
\tilde{P}_{i, t+1}=\tilde{D}_{i, t+1} \mu_{i t}
$$

where the random variable $\widetilde{P}_{i, t+1}$ represents the next equilibrium price of stock $i$ at time $t+1$.

To summarize, equation (11) proposes that random prices are directly and stochastically related to next dividends. To put it simply, prices and dividends are cointegrated.

This result is important because it: (1) permits the release of future random prices from the equilibrium conditions given by the CCAPM; and (2) shows that 
these equilibrium conditions can be expressed using only two random variables (dividends and consumption), for a single period.

\subsection{Equilibrium dividend growth for a single period}

Recursively, the present value of all future dividends, expressed by equation (4), is equivalent to the following single period equation:

$$
P_{i t}=E_{t}\left[\tilde{M}_{t+1}\left(\tilde{P}_{i, t+1}+\tilde{D}_{i, t+1}\right)\right]
$$

where the stochastic discount factor corresponds to the intertemporal marginal rate of substitution between $t$ and $t+1, \tilde{M}_{t+1}$, which is, for the time-separable utility function, such that: $\tilde{M}_{t+1} \equiv \delta U^{\prime}\left(\tilde{C}_{t+1}\right) / U^{\prime}\left(C_{t}\right)$.

Integrating equations (8) and (11) into the single period expression of an asset price, as formulated by equation (12), allows us to write that:

$$
\mu_{i t} D_{i t}=E_{t}\left[\tilde{M}_{t+1}\left(\mu_{i t} \tilde{D}_{i, t+1}+\tilde{D}_{i, t+1}\right)\right]
$$

After simple manipulations, noting that $\tilde{g}_{i, t+1} \equiv \tilde{D}_{i, t+1} / D_{i t}-1$, we get:

$$
1=E_{t}\left[\tilde{M}_{t+1}\left(1+\tilde{g}_{i, t+1}\right)\left(1+1 / \mu_{i t}\right)\right],
$$

where $\tilde{g}_{i, t+1}$ represents the dividend growth rate of stock $i$, between time $t$ and $t+1$. Thus, given the available information in time $t$, we have:

$$
1 /\left(1+1 / \mu_{i t}\right)=E_{t}\left[\tilde{M}_{t+1}\left(1+\tilde{g}_{i, t+1}\right)\right]
$$

and the mathematical definition of covariance indicates that:

$$
1 /\left(1+1 / \mu_{i t}\right)=\operatorname{COV}_{t}\left[\tilde{M}_{t+1}, 1+\tilde{g}_{i, t+1}\right]+E_{t}\left[\tilde{M}_{t+1}\right] E_{t}\left[1+\tilde{g}_{i, t+1}\right],
$$

which permits us to isolate the expected dividend growth rate, under equilibrium condition, as follows:

$$
E_{t}\left[1+\tilde{g}_{i, t+1}\right]=\frac{1 /\left(1+1 / \mu_{i t}\right)}{E_{t}\left[\tilde{M}_{t+1}\right]}-\frac{\operatorname{COV}_{t}\left[\tilde{M}_{t+1}, 1+\tilde{g}_{i, t+1}\right]}{E_{t}\left[\tilde{M}_{t+1}\right]}
$$


In equilibrium, according to the standard consumption-based model, expected asset returns are proportional to the covariance of returns with discount factors (see, for example, Cochrane, 2005, p. 15). In the same manner, equation (17) reveals that the equilibrium dividends growth rate is linearly related to the covariance of the dividend growth rate with the discount factor.

Integrating the definition of the intertemporal marginal rate of substitution between $t$ and $t+1$, in the covariance term, shows that:

$$
E_{t}\left[1+\tilde{g}_{i, t+1}\right]=\frac{1 /\left(1+1 / \mu_{i t}\right)}{E_{t}\left[\tilde{M}_{t+1}\right]}-\frac{\operatorname{COV}_{t}\left[\delta U^{\prime}\left(\tilde{C}_{t+1}\right) / U^{\prime}\left(C_{t}\right), 1+\tilde{g}_{i, t+1}\right]}{E_{t}\left[\tilde{M}_{t+1}\right]} .
$$

As noted by Cochrane (2005, p. 19), the consumption growth rate represents a more concrete variable than marginal utility. To express the last equilibrium condition with consumption growth rate, we suppose, (as in Rubinstein, 1976, and many others after) that the dividend of a stock and the aggregate consumption are bivariate normally distributed. Therefore, based on the lemma of Stein, we can rewrite the last equation in this way: ${ }^{8}$

$$
E_{t}\left[1+\tilde{g}_{i, t+1}\right]=\frac{1 /\left(1+1 / \mu_{i t}\right)}{E_{t}\left[\tilde{M}_{t+1}\right]}-\frac{\delta E_{t}\left[U^{\prime \prime}\left(\tilde{C}_{t+1}\right)\right] \operatorname{COV} V_{t}\left[\tilde{C}_{t+1}, 1+\tilde{g}_{i, t+1}\right]}{U^{\prime}\left(C_{t}\right) E_{t}\left[\tilde{M}_{t+1}\right]}
$$

Multiplying both sides of equation (19) by the current aggregate consumption $\left(C_{t}\right)$ shows, after simple manipulations, that:

$$
E_{t}\left[1+\tilde{g}_{i, t+1}\right]=\frac{1 /\left(1+1 / \mu_{i t}\right)}{E_{t}\left[\tilde{M}_{t+1}\right]}-\frac{\delta C_{t} E_{t}\left[U^{\prime \prime}\left(\tilde{C}_{t+1}\right)\right] C O V_{t}\left[1+\tilde{g}_{t+1}, 1+\tilde{g}_{i, t+1}\right]}{U^{\prime}\left(C_{t}\right) E_{t}\left[\tilde{M}_{t+1}\right]}
$$

where $\tilde{g}_{t+1}$ represents the growth rate of aggregate consumption, between time $t$ and $t+1\left(\tilde{g}_{t+1} \equiv \tilde{C}_{t+1} / C_{t}-1\right)$.

Equation (20) indicates that the expected dividend growth rate of a stock is linearely related to its dividends-consumption covariance. The relationship is positive because the second derivative of the utility function must be negative, by construction, and because the other values that define the slope of the relationship ( $\delta, C$, etc) are all positive, by definition. This result is consistent with the notion that big old firms that have low risk, and low sensibility to aggregate consumption (reflecting economic activities), present low expected dividend growth (see, for example, Grullon et al., 2002). In the next section, we will develop this intuitive 
relationship, by first isolating the covariance term above, and then integrating the earnings, to finally express the dividends-risk relationship in terms of dividend payout ratios and accounting betas.

\section{Dividend, earnings, and accounting risk}

If firms are risk averse and cautious, then those operating in a high level of uncertainty will pay lower dividends in order to have enough retained earnings for bad earnings years (see, also, Hoberg and Prabhala, 2009). This section demonstrates that the dividend payout ratio of a firm depends on its earnings risk. The intuition behind this relationship can be summarized as follows: if we postulate that dividends are naturally associated to earnings, and if we assume that dividend policies are related to risks, then it makes sense to measure risk directly from earnings, in a dividend-risk model. Our demonstration begins by isolating the dividendsconsumption covariance term obtained from our equilibrium framework. We then integrate earnings into the covariance term, via the dividends-earnings process proposed previously. Thereafter, we derive the dividend-risk relationship assuming the existence of a firm for which dividends (or earnings) are not correlated with aggregate consumption.

\subsection{Covariance and earnings}

Our previous development suggests that dividends and aggregate consumption are correlated. Indeed, if we isolate the dividends-consumption covariance term obtained from the equilibrium expression of the expected dividend growth rate of a stock, as formulated by equation (20), then we can write:

$$
\begin{gathered}
{\left[E_{t}\left[1+\tilde{g}_{i, t+1}\right]-\frac{1 /\left(1+1 / \mu_{i t}\right)}{E_{t}\left[\tilde{M}_{t+1}\right]}\right]\left[\frac{(-1) \delta C_{t} E_{t}\left[U^{\prime \prime}\left(\tilde{C}_{t+1}\right)\right]}{U^{\prime}\left(C_{t}\right) E_{t}\left[\tilde{M}_{t+1}\right]}\right]^{-1}} \\
=\operatorname{COV}_{t}\left[1+\tilde{g}_{t+1}, 1+\tilde{g}_{i, t+1}\right]
\end{gathered}
$$

or, to simplify the notation:

$$
\sigma_{c i t}=C O V_{t}\left[1+\widetilde{g}_{t+1}, 1+\widetilde{g}_{i, t+1}\right]
$$

where $\sigma_{c i t} \equiv\left[E_{t}\left[1+\tilde{g}_{i, t+1}\right]-\frac{1 /\left(1+1 / \mu_{i t}\right)}{E_{t}\left[\tilde{M}_{t+1}\right]}\right]\left[\frac{(-1) \delta C_{t} E_{t}\left[U^{\prime \prime}\left(\tilde{C}_{t+1}\right)\right]}{U^{\prime}\left(C_{t}\right) E_{t}\left[\tilde{M}_{t+1}\right]}\right]^{-1}$

Using the definition of mathematical covariance, we can also write: 


$$
\sigma_{c i t}=E_{t}\left[\left(1+\tilde{g}_{t+1}\right)\left(1+\tilde{g}_{i, t+1}\right)\right]-E_{t}\left[1+\tilde{g}_{t+1}\right] E_{t}\left[1+\tilde{g}_{i, t+1}\right],
$$

or:

$$
E_{t}\left[1+\tilde{g}_{t+1}\right] E_{t}\left[1+\tilde{g}_{i, t+1}\right]+\sigma_{c i t}=E_{t}\left[\left(1+\tilde{g}_{t+1}\right)\left(1+\tilde{g}_{i, t+1}\right)\right]
$$

Since the dividend of stock $i$, at time $t$, is known, it can be passed through the conditional expectation operator, to get, after simple manipulations:

$$
E_{t}\left[1+\tilde{g}_{t+1}\right] E_{t}\left[\tilde{D}_{i, t+1}\right]+\sigma_{c i t} D_{i t}=E_{t}\left[\left(1+\tilde{g}_{t+1}\right) \tilde{D}_{i, t+1}\right]
$$

Dividing by the expected value $E_{t}\left[\tilde{D}_{i, t+1}\right]$, on each side of equation (25), reveals that:

$$
E_{t}\left[1+\tilde{g}_{t+1}\right]+\sigma_{c i t} D_{i t} / E_{t}\left[\tilde{D}_{i, t+1}\right]=E_{t}\left[\left(1+\tilde{g}_{t+1}\right) \tilde{D}_{i, t+1}\right] / E_{t}\left[\tilde{D}_{i, t+1}\right]
$$

In accordance with equation (2a), and the dividends-earnings process assumed previously, we can integrate the current earnings and the expected earnings of the stock in equation (26), as follows:

$$
\begin{aligned}
& E_{t}\left[1+\tilde{g}_{t+1}\right]+\sigma_{c i t} D_{i t} /\left(D_{i t} / X_{i t}\right) E_{t}\left[\tilde{X}_{i, t+1}\right] \\
& =E_{t}\left[\left(1+\tilde{g}_{t+1}\right) \tilde{D}_{i, t+1}\right] /\left(D_{i t} / X_{i t}\right) E_{t}\left[\tilde{X}_{i, t+1}\right] .
\end{aligned}
$$

After manipulations, the last equation also indicates that:

$$
\begin{gathered}
E_{t}\left[1+\tilde{g}_{t+1}\right]\left(D_{i t} / X_{i t}\right)+\sigma_{c i t} D_{i t} / E_{t}\left[\tilde{X}_{i, t+1}\right], \\
=E_{t}\left[\left(1+\tilde{g}_{t+1}\right) \tilde{D}_{i, t+1}\right] / E_{t}\left[\tilde{X}_{i, t+1}\right] .
\end{gathered}
$$

To simplify the notation, equation (28) can be rewritten as:

$$
E_{t}\left[1+\tilde{g}_{t+1}\right]\left(D_{i t} / X_{i t}\right)+\sigma_{c i} D_{i t} / \bar{X}_{i, t+1}=E_{t}\left[\left(1+\tilde{g}_{t+1}\right) \tilde{D}_{i, t+1} / \bar{X}_{i, t+1}\right]
$$

where $\bar{X}_{i, t+1} \equiv E_{t}\left[\tilde{X}_{i, t+1}\right]$. Adding $E_{t}\left[1+\tilde{g}_{t+1}\right]$ to both sides of equation (29), shows that:

$$
E_{t}\left[1+\tilde{g}_{t+1}\right]+E_{t}\left[1+\tilde{g}_{t+1}\right]\left(D_{i t} / X_{i t}\right)+\sigma_{c i t} D_{i t} / \bar{X}_{i, t+1}
$$




$$
=E_{t}\left[1+\tilde{g}_{t+1}\right]+E_{t}\left[\left(1+\tilde{g}_{t+1}\right) \tilde{D}_{i, t+1} / \bar{X}_{i, t+1}\right]
$$

Rearranging indicates that:

$$
\begin{gathered}
E_{t}\left[1+\tilde{g}_{t+1}\right]-E_{t}\left[\left(1+\tilde{g}_{t+1}\right) \tilde{D}_{i, t+1} / \bar{X}_{i, t+1}\right] \\
=E_{t}\left[1+\tilde{g}_{t+1}\right]-E_{t}\left[1+\tilde{g}_{t+1}\right]\left(D_{i t} / X_{i t}\right)-\sigma_{c i t} D_{i t} / \bar{X}_{i, t+1},
\end{gathered}
$$

or, more simply:

$$
\begin{gathered}
E_{t}\left[\left(1+\tilde{g}_{t+1}\right)\left(1-\tilde{D}_{i, t+1} / \bar{X}_{i, t+1}\right)\right] \\
=E_{t}\left[1+\tilde{g}_{t+1}\right]\left(1-D_{i t} / X_{i t}\right)-\sigma_{c i t} D_{i t} / \bar{X}_{i, t+1} .
\end{gathered}
$$

Consequently, equation (32) shows, after simple manipulations, a particular form of the familiar Euler equation, in which the central random variables are driven by aggregate consumption, and stock dividends (relative to earnings). That is to say:

$$
E_{t}\left[\left(1+\tilde{g}_{t+1}\right) \tilde{Y}_{i, t+1}\right]=1
$$

where $\tilde{Y}_{i, t+1} \equiv \frac{1-\tilde{D}_{i, t+1} / \bar{X}_{i, t+1}}{E_{t}\left[1+\tilde{g}_{t+1}\right]\left(1-D_{i t} / X_{i t}\right)-\sigma_{c i t} D_{i t} / \bar{X}_{i, t+1}}$.

\subsection{No correlation with consumption}

Now, suppose that we can identify a stock which has dividends that are uncorrelated with consumption. This means that its dividends (or earnings) have a zero covariance with aggregate consumption, and are not affected by economic fluctuations. For such a theoretical security, we have:

$$
E_{t}\left[\left(1+\tilde{g}_{t+1}\right) \tilde{Y}_{z, t+1}\right]=1
$$

where the index $z$ denotes the security which has no correlation with aggregate consumption. Therefore, equation (33) minus equation (34), gives:

$$
E_{t}\left[\left(1+\tilde{g}_{t+1}\right)\left(\tilde{Y}_{i, t+1}-\tilde{Y}_{z, t+1}\right)\right]=0
$$

and the mathematical definition of covariance implies that: 


$$
\operatorname{COV}_{t}\left[1+\tilde{g}_{t+1}, \tilde{Y}_{i, t+1}-\tilde{Y}_{z, t+1}\right]=-E_{t}\left[1+\tilde{g}_{t+1}\right] E_{t}\left[\tilde{Y}_{i, t+1}-\tilde{Y}_{z, t+1}\right],
$$

or, after manipulations:

$$
E_{t}\left[\tilde{Y}_{i, t+1}\right]=E_{t}\left[\tilde{Y}_{z, t+1}\right]-\frac{\operatorname{COV}_{t}\left[1+\tilde{g}_{t+1}, \tilde{Y}_{i, t+1}\right]}{E_{t}\left[1+\tilde{g}_{t+1}\right]}
$$

Multiplying on each side by the dominator of variable $\tilde{Y}_{i, t+1}$, we get

$$
\begin{gathered}
E_{t}\left[1-\tilde{D}_{i, t+1} / \bar{X}_{i, t+1}\right]= \\
-\frac{E_{t}\left[\tilde{Y}_{z, t+1}\right]\left(E_{t}\left[1+\tilde{g}_{t+1}\right]\left(1-D_{t}\left[1+\tilde{g}_{t+1}, 1-\tilde{D}_{i, t+1} / \bar{X}_{i, t+1}\right]-\sigma_{c i t} D_{i t} / \bar{X}_{i, t+1}\right)\right.}{E_{t}\left[1+\tilde{g}_{t+1}\right]}
\end{gathered}
$$

or using the basic properties of mathematical covariance:

$$
\begin{gathered}
E_{t}\left[1-\widetilde{D}_{i, t+1} / \bar{X}_{i, t+1}\right]=E_{t}\left[\tilde{Y}_{z, t+1}\right]\left(E_{t}\left[1+\tilde{g}_{t+1}\right]\left(1-D_{i t} / X_{i t}\right)-\sigma_{c i t} D_{i t} / \bar{X}_{i, t+1}\right) \\
+\operatorname{COV}_{t}\left[1+\tilde{g}_{t+1}, \tilde{D}_{i, t+1} / \bar{X}_{i, t+1}\right] / E_{t}\left[1+\tilde{g}_{t+1}\right]
\end{gathered}
$$

Integrating equation (32) in equation (39), indicates that:

$$
\begin{gathered}
E_{t}\left[1-\tilde{D}_{i, t+1} / \bar{X}_{i, t+1}\right]=E_{t}\left[\tilde{Y}_{z, t+1}\right]\left(E_{t}\left[\left(1+\tilde{g}_{t+1}\right)\left(1-\tilde{D}_{i, t+1} / \bar{X}_{i, t+1}\right)\right]\right) \\
+\operatorname{COV}_{t}\left[1+\tilde{g}_{t+1}, \tilde{D}_{i, t+1} / \bar{X}_{i, t+1}\right] / E_{t}\left[1+\tilde{g}_{t+1}\right]
\end{gathered}
$$

and the mathematical definition of covariance implies that:

$$
\begin{gathered}
E_{t}\left[1-\tilde{D}_{i, t+1} / \bar{X}_{i, t+1}\right] \\
=E_{t}\left[\tilde{Y}_{z, t+1}\right]\left(C O V_{t}\left[1+\tilde{g}_{t+1}, 1-\tilde{D}_{i, t+1} / \bar{X}_{i, t+1}\right]+E_{t}\left[1+\tilde{g}_{t+1}\right] E_{t}\left[1-\tilde{D}_{i, t+1} / \bar{X}_{i, t+1}\right]\right) \\
+\operatorname{COV}_{t}\left[1+\tilde{g}_{t+1}, \tilde{D}_{i, t+1} / \bar{X}_{i, t+1}\right] / E_{t}\left[1+\tilde{g}_{t+1}\right] .
\end{gathered}
$$

Using, again, the basic properties of covariance, equation (41) becomes:

$$
E_{t}\left[1-\tilde{D}_{i, t+1} / \bar{X}_{i, t+1}\right]
$$




$$
\begin{gathered}
=E_{t}\left[\tilde{Y}_{z, t+1}\right]\left(E_{t}\left[1+\tilde{g}_{t+1}\right] E_{t}\left[1-\tilde{D}_{i, t+1} / \bar{X}_{i, t+1}\right]-\operatorname{COV}_{t}\left[1+\tilde{g}_{t+1}, \tilde{D}_{i, t+1} / \bar{X}_{i, t+1}\right]\right) \\
+\operatorname{COV}_{t}\left[1+\tilde{g}_{t+1}, \tilde{D}_{i, t+1} / \bar{X}_{i, t+1}\right] / E_{t}\left[1+\tilde{g}_{t+1}\right] .
\end{gathered}
$$

After simple, manipulations, we can write:

$$
\begin{gathered}
E_{t}\left[1-\tilde{D}_{i, t+1} / \bar{X}_{i, t+1}\right] \\
=E_{t}\left[\tilde{Y}_{z, t+1}\right] E_{t}\left[1+\tilde{g}_{t+1}\right] E_{t}\left[1-\tilde{D}_{i, t+1} / \bar{X}_{i, t+1}\right] \\
+\left(1 / E_{t}\left[1+\tilde{g}_{t+1}\right]-E_{t}\left[\tilde{Y}_{z, t+1}\right]\right) C O V_{t}\left[1+\tilde{g}_{t+1}, \tilde{D}_{i, t+1} / \bar{X}_{i, t+1}\right],
\end{gathered}
$$

or, rearranging:

$$
\begin{gathered}
E_{t}\left[1-\tilde{D}_{i, t+1} / \bar{X}_{i, t+1}\right]\left(1-E_{t}\left[\tilde{Y}_{z, t+1}\right] E_{t}\left[1+\widetilde{g}_{t+1}\right]\right) \\
=\left(1 / E_{t}\left[1+\tilde{g}_{t+1}\right]-E_{t}\left[\tilde{Y}_{z, t+1}\right]\right) C O V_{t}\left[1+\tilde{g}_{t+1}, \tilde{D}_{i, t+1} / \bar{X}_{i, t+1}\right] .
\end{gathered}
$$

Integrating equation (1a), given by the dividends-earnings process, allows us to reveal the implications of future random earnings, as shown below:

$$
\begin{gathered}
E_{t}\left[1-\left(d_{i t} \tilde{X}_{i, t+1}+\tilde{\varepsilon}_{i, t+1}\right) / \bar{X}_{i, t+1}\right]\left(1-E_{t}\left[\tilde{Y}_{z, t+1}\right] E_{t}\left[1+\tilde{g}_{t+1}\right]\right) \\
=\left(1 / E_{t}\left[1+\tilde{g}_{t+1}\right]-E_{t}\left[\tilde{Y}_{z, t+1}\right]\right) C O V_{t}\left[1+\tilde{g}_{t+1},\left(d_{i t} \tilde{X}_{i, t+1}+\tilde{\varepsilon}_{i, t+1}\right) / \bar{X}_{i, t+1}\right] .
\end{gathered}
$$

Given the standard assumptions related to the usual residual random term $(\tilde{\varepsilon})$, we can also reduce the last equation in this manner:

$$
\begin{gathered}
E_{t}\left[1-d_{i t} \tilde{X}_{i, t+1} / \bar{X}_{i, t+1}\right]\left(1-E_{t}\left[\tilde{Y}_{z, t+1}\right] E_{t}\left[1+\tilde{g}_{t+1}\right]\right) \\
=\left(1 / E_{t}\left[1+\tilde{g}_{t+1}\right]-E_{t}\left[\tilde{Y}_{z, t+1}\right]\right) C O V_{t}\left[1+\tilde{g}_{t+1}, d_{i t} \tilde{X}_{i, t+1} / \bar{X}_{i, t+1}\right] .
\end{gathered}
$$

Dividing each side by $d_{i t}$, and using the basic properties of mathematical expectation, yields:

$$
\begin{gathered}
\left(d_{i t}^{-1}-1\right)\left(1-E_{t}\left[\tilde{Y}_{z, t+1}\right] E_{t}\left[1+\tilde{g}_{t+1}\right]\right) \\
=\left(1 / E_{t}\left[1+\tilde{g}_{t+1}\right]-E_{t}\left[\tilde{Y}_{z, t+1}\right]\right) C O V_{t}\left[1+\tilde{g}_{t+1}, \tilde{X}_{i, t+1} / \bar{X}_{i, t+1}\right] .
\end{gathered}
$$


Isolating the dividend payout ratio of the stock (or its inverse), gives:

$$
d_{i t}^{-1}=1+\frac{1 / E_{t}\left[1+\tilde{g}_{t+1}\right]-E_{t}\left[\tilde{Y}_{z, t+1}\right]}{1-E_{t}\left[\tilde{Y}_{z, t+1}\right] E_{t}\left[1+\tilde{g}_{t+1}\right]} \operatorname{COV} V_{t}\left[1+\tilde{g}_{t+1}, \tilde{X}_{i, t+1} / \bar{X}_{i, t+1}\right]
$$

Multiplying both side of equation (48) by the conditional expectation $E_{t}\left[1+\widetilde{g}_{t+1}\right]$ allows us to write, after simple manipulations:

$$
d_{i t}^{-1}=1+\operatorname{COV}_{t}\left[\widetilde{G}_{t+1}, \tilde{X}_{i, t+1} / \bar{X}_{i, t+1}\right]
$$

with $\tilde{G}_{t+1} \equiv\left(1+\tilde{g}_{t+1}\right) / E_{t}\left[1+\tilde{g}_{t+1}\right]$. In the same manner, multiplying each side of equation (49) by the conditional expectation $E_{t}\left[1+\tilde{g}_{i, t+1}^{E}\right]$, allows us to write:

$$
d_{i t}^{-1}=1+\operatorname{COV}_{t}\left[\tilde{G}_{t+1}, \widetilde{G}_{i, t+1}^{E}\right]
$$

with $\widetilde{G}_{i, t+1}^{E} \equiv\left(1+\tilde{g}_{i, t+1}^{E}\right) / E_{t}\left[1+\tilde{g}_{i, t+1}^{E}\right]$, where $\tilde{g}_{i, t+1}^{E}$ is the earnings growth rate of stock $i$, between time $t$ and $t+1\left(\tilde{g}_{i, t+1}^{E} \equiv \tilde{X}_{i, t+1} / X_{i t}-1\right)$. $^{9}$

Equation (50) clearly establishes that the inverse of the current dividend payout ratio of a firm is positively and directly proportional to the covariance of its earnings to aggregate consumption. This simple relationship presents several interesting implications. For example, it makes it possible to easily identify the value of the current dividend payout ratio for the security which has no correlation with aggregate consumption (this value is 1). In the same manner, it makes it possible to identify the value of the payout ratio in a context of certainty (this value is the same: 1). In a context of uncertainty, the higher the earnings-consumption covariance is, the higher the inverse of the payout ratio is. Thus, if we postulate that dividends and risk are negatively related (as many authors suggest), then, in accordance with equation (50), the earnings-consumption covariance represents a measure of risk.

\subsection{Aggregate level}

To facilitate the application and interpretation of the last relationship, let us first recognize that, on an aggregate level, we can write:

$$
d_{m t}^{-1}=1+\operatorname{COV}_{t}\left[\tilde{G}_{t+1}, \tilde{G}_{m, t+1}^{E}\right]
$$

where, again, the index $m$ represents the aggregate level for the entire market. Introducing equation (51) in equation (50), gives: 


$$
d_{i t}^{-1}=1+\left(d_{m t}^{-1}-1\right) C O V_{t}\left[\tilde{G}_{t+1}, \tilde{G}_{i, t+1}^{E}\right] / C O V_{t}\left[\tilde{G}_{t+1}, \tilde{G}_{m, t+1}^{E}\right]
$$

Therefore, taking the inverse of each side of equation (52), we finally obtain this simple and easy-to-apply formula:

$$
d_{i t}=\frac{1}{1+\lambda_{t} \beta_{i t}^{E}},
$$

with,

$$
\begin{aligned}
& \lambda_{t} \equiv d_{m t}^{-1}-1, \\
& \beta_{i t}^{E} \equiv \operatorname{COV}_{t}\left[\tilde{G}_{t+1}, \tilde{G}_{i, t+1}^{E}\right] / \operatorname{COV}_{t}\left[\tilde{G}_{t+1}, \widetilde{G}_{m, t+1}^{E}\right]
\end{aligned}
$$

The parameter $\lambda_{t}$ is determined by the market dividend payout ratio at time $t\left(d_{m t}\right)$. Its value is positive if we postulate that the aggregate earnings for the entire market are naturally superior (years after years) to their corresponding dividends. ${ }^{10}$ The parameter $\beta_{i t}^{E}$ represents the earnings consumption beta of stock $i$, given the available information at time $t$, as in Bergeron et al. (2018, p. 160). It measures how sensitive a firm's earnings are to aggregate consumption. It can be viewed as the coefficient of earning sensitivity to economic fluctuations. In this sense, it is consistent with the important concept of accounting beta, which corresponds to a measure of risk, or, more precisely, to a measure of systematic earnings risk. ${ }^{11}$

Equation (53) represents our main result. It shows that the dividend payout ratio of a stock is negatively related to its earnings consumption beta, obtained from the covariance between the firm's earnings and aggregate consumption.

This result is fully consistent with an anticipated negative relationship between dividend policy and risk. Here, dividend policy is represented by the dividend payout ratio, and risk is measured by the earnings consumption beta. For example, if the earnings consumption beta of a particular firm is zero, then its dividend payout ratio should be equal to $100 \%$, and all of its earnings should be distributed to shareholders. If the earnings-consumption beta of the firm is the same as that of the market, then its value is 1 , and the firm's payout ratio should be equivalent to the market dividend payout ratio. ${ }^{12}$ Similarly to Bergeron et al. (2015, p. 187), this relationship could be illustrated by a curve that approaches the horizontal axis asymptotically. However, in Bergeron et al. (2015) no link was shown to earnings risk. Furthermore, in Bergeron et al. (2015) the illustrated relationship is based on a particular case, where the number of factors that are supposed to influence dividend growth are arbitrarily 
reduced to 1, and where the unique factor is arbitrarily made equivalent to the aggregate consumption growth.

Concerning the difficulties in identifying the factors that influence a variable (earnings, dividends or returns), see, for example, Breeden (1979). Breeden shows that Merton's multi-beta pricing equation (Merton, 1973) can be collapsed into a single-beta equation, where the instantaneous expected excess return on any security is proportional to its beta (or covariance) with respect to aggregate consumption. The fact that Breeden's model involves a single beta relative to a specific variable, rather than many betas measured relative to unspecified variables, made it easier to test and to implement. Therefore, one of the important contributions of Breeden (relative to Merton), was to simplify (or collapse) a complex multi-beta model into a single-beta model. In the canonical CCAPM, formulated by Breeden, aggregate consumption includes all state variables needed to describe the relevant characteristics of investment returns, and the standard consumption beta integrates the multiple dimensions of risk. Our model presents similar characteristics (with earnings). It suggests that aggregate consumption includes all economic factors that influence earnings, and demonstrates that the earnings consumption beta integrates the multiple dimensions of risk, in a dividend decision context.

In accordance with our model, the optimal dividend policy implies the following steps: 1) establish the evolution of aggregate consumption growth rates, the earnings growth rates of the entire market, and the earnings growth rates of the firm; 2) estimate the resulting earnings consumption beta for the firm; 3 ) determine the average dividend payout ratio on the market; and 4) calculate the target dividend payout ratio of the firm as proposed by the simple formula, above. The proportion of earnings distribution to shareholders will be superior (inferior) to the global payout ratio on the market, if the estimation of the systematic earnings risk of the firm is inferior (superior) to the average (equals to 1). All these steps will be made given the available information at that time, and will be revaluated periodically, as they should be, in an intertemporal context. For example, if we estimate that the earnings consumption beta of a particular firm is equal to 1.5 in 2018, and if we determine that the average dividend payout ratio in the United States was around $40 \%$, during this period, then we can conclude that the dividend payout ratio should be approximately $31 \%$, according to equation (53). If we re-estimate, the following year, that the earnings risk is actually lower, given the available information, then the target payout ratio will be higher.

The dividend decision procedure developed here, presents other interesting characteristics from a theoretical or a practical point of view. For instance, according to Nekrasov and Shroff (2009, p. 1984), if a firm's intrinsic value is determined by fundamental economic variables such as earnings cash flows, then it makes sense to measure risk directly from earnings, in a valuation context. This relevant premise is 
also valid for our dividend distribution model. Indeed, if we postulate that dividends are inseparably bound to earnings cash flows, and if we accept that dividend distribution is negatively related to risk, then it also makes sense to measure risk directly from earnings, in a dividend decision context.

In addition, as we noted earlier, Da's empirical study (2009) indicates that the covariance between earnings and aggregate consumption represents an appropriate measure of risk, and can explains $58 \%$ of the cross-sectional variation in in expected returns. Thus, we can argue that our model represents a straightforward application of Da's recent results. In the same manner, we can also argue that our model use a novel theoretical measure of risk, empirically validated.

Moreover, as mentioned by Da (2009), estimating risk with earnings cash flows instead of returns has the following advantages. Firstly, in the short term, returns may temporarily deviate from their normal value due to market price instability (or market mispricing). Secondly, in typical asset pricing models, prices and returns are fundamentally evaluated using dividends or earnings cash flows. The dividend model derived in this section is also consistent with these characteristics. In this sense, our model supports the use of accounting variables in estimating risk.

\section{Conclusion}

Our goal, in this paper, was to develop a theoretical model of the relationship between dividend policy and earnings risk. Our development was similar to any asset pricing model that, given a solid economic framework, derives the required rate of return for an asset, considering the level of risk.

Using the fundamental framework of the CCAPM, we showed that the target dividend payout ratio of a firm is negatively related to its earnings consumption beta, obtained from the covariance between earnings and aggregate consumption. According to this result, we suggest that risk measured with earnings influences dividend policy. We also suggest that our model offers several interesting characteristics. For example, the model indicates the appropriate measure of risk for dividend decisions, in an intertemporal context. In addition, our main result indicates that the earnings consumption beta integrates the multiple dimension of earnings risk. Moreover, the model allows us to identify the theoretical payout ratio in a context of certainty (100\%), and shows that a high-risk firm, with earnings that are very sensitive to economic fluctuations, should tend to a zero distribution policy. Furthermore, the model's parameters are easy to interpret, and easy to obtain (from firm and market data). Likewise, integration of an earnings risk measure in a 
dividends-risk model seems intuitively attractive, if we accept that dividends and earnings are inseparable. Additionally, the model utilizes a recent and performing measure of accounting risk, according to $\mathrm{Da}$ (2009). In this vein, the model legitimates (or supports) the use of accounting variables for estimating risk.

Finally, the derivation of the model assumes that the dividend of a stock and aggregate consumption are bivariate normally distributed. For future research, it may be suitable to see how we could relax this restrictive assumption. It also may be suitable to see how we could relax the assumption of an additive time-separable utility function.

\section{References}

Abdoh, M. and Varela O. (2017) 'Product market competition, idiosyncratic and systematic volatility', Journal of Corporate Finance, Vol. 43 No. 1, pp. 500-513.

Baginski, P. and Wahlen, J.M. (2003) 'Residual income risk, intrinsic values, and share prices', The Accounting Review, Vol. 78 No. 1, pp. 327-351.

Bajaj, M. and Vijh, A.M. (1990) 'Dividend clienteles and the information content of dividend changes’, Journal of Financial Economics, Vol. 26 No. 2, pp. 193-219.

Baker, H.K. and Weigand, R. (2015) 'Corporate dividend policy revisited', Managerial Finance, Vol. 41 No. 2, pp. 126-144.

Bakshi, G. and Chen, Z. (2005) 'Stock valuation in dynamic economies', Journal of Financial Markets, Vol. 8 No. 2, pp. 111-151.

Ball, R. and Sadka, G. (2015) 'Aggregate earnings and why they matter', Journal of Accounting Literature, Vol. 34 No. 1, pp. 39-57.

Bansal, R. and Kiku, D. (2011) 'Cointegration and long-run asset allocation', Journal of Business and Economic Statistics, Vol. 29 No. 1, pp. 161-173.

Baskin, J. (1989) 'Dividend policy and the volatility of common stocks', Journal of Portfolio Management, Vol. 15 No. 3, pp. 19-25.

Bhattacharya, S. (1979) 'Imperfect information, dividend policy, and "The bird in the hand" Fallacy', Bell Journal of Economics, Vol. 10 No. 1, pp. 259-270.

Beaver, W., Kettler, P. and Scholes, M. (1970) 'The association between market determined and accounting determined risk measures', The Accounting Review, Vol. 45 No. 4, pp. 654-682.

Beaver, W. and Manegold, J. (1975) 'The association between market-determined and accountingdetermined measures of systematic risk: some further evidence', Journal of Financial and Quantitative Analysis, Vol. 10 No. 2, pp. 231-284.

Bergeron, C. (2013) 'Dividend sensitivity to economic factors, stock valuation, and long-run risk', Finance Research Letters, Vol. 11 No. 3, pp. 184-195.

Bergeron, C., Gueyie, J.P. and Sedzro, K. (2015) 'Dividend multifactor process, long-run risk and payout ratios', American Journal of Finance and Accounting, Vol. 4 No. 2, pp. 172-190. 
Bergeron, C., Gueyie, J.P. and Sedzro, K. (2018) 'Earnings-consumption betas and stock valuation', American Journal of Finance and Accounting, Vol. 5 No. 2, pp. 151-172.

Black, F. (1976) 'The dividend puzzle', Journal of Portfolio Management, Vol. 2 No. 2, pp. 5-8.

Breeden, D.T. (1979) 'An intertemporal asset pricing model with stochastic consumption and investment opportunities', Journal of Financial Economics, Vol. 7 No. 3, pp. 265-296.

Carter, M.S. (2008) 'The relationship between dividend payouts and systematic risk: a mathematical approach', Academy of Accounting and Financial Studies Journal, Vol. 12 No. 2, pp. 93-100.

Cochrane, J.H. (2005), Asset Pricing. Princeton University Press, Princeton N.J.

Da, Z. (2009), 'Cash flow, consumption risk, and the cross-section of stock returns', The Journal of Finance, Vol. 64 No. 2, pp. 923-956.

Da, Z. and Warachka, M.C. (2009), 'Cashflow risk, systematic earnings revisions, and the crosssection of stock returns', Journal of Financial Economics, Vol. 94 No. 3, pp. 448-468.

Dong, M. and Hirshleifer, D. (2005) 'A generalized earnings-based stock valuation model', The Manchester School, Vol. 73 No. 9, pp. 1-31.

Eades, K.M. (1982) 'Empirical Evidence on dividends as a signal of firm value', Journal of Financial and Quantitative Analysis, Vol. 17 No. 4, pp. 471-500.

Epstein, L. and Zin, S. (1989) 'Substitution, risk aversion and the temporal behavior of consumption and asset returns: A theoretical framework’, Econometrica, Vol. 57 No. 4, pp. 937-969.

Gordon, M. (1959) 'Dividends, earnings, and stock prices', Review of Economics and Statistics, Vol. 41 No. 2, pp. 99-105.

Goyal, A. (2012) 'Empirical cross-sectional asset pricing: a survey', Financial Markets and Portfolio Management, Vol. 26 No. 1, pp. 3-38.

Grullon, G., Michaely R. and Swaminathan, B. (2002) 'Are dividend changes a sign of maturity?', Journal of Business, Vol. 75 No. 3, pp. 387-424.

Hoberg, G. and Prabhala, N. (2009) 'Disappearing dividends, catering, and risk', The Review of Financial Studies, Vol. 22 No. 1, pp. 79-116.

Hurley, J.W. (2013) 'Calculating first moments and confidence intervals for generalized stochastic dividend discount models', Journal of Mathematical Finance, Vol. 3 No. 2, pp. 57-68.

Hussainey, K., Mgbame, C.O. and Chijoke-Mgbame, A.M. (2011) 'Dividend policy and share price volatility: UK evidence', The Journal of Risk Finance, Vol. 12 No. 1, pp. 57-68.

Ismail, B.E. and Kim, M.K. (1989) 'On the association of cash flow variables with market risk: further evidence', The Accounting Review, Vol. 64 No. 1, pp. 125-136.

Jagannathan, M., Stephens, C.P. and Weisbach M.S. (2000) 'Financial flexibility and the choice between dividends and stock repurchases", Journal of Financial Economics, Vol. 57 No. 3, pp. 355-384.

Jensen, M.C. (1986) 'Agency costs of free cash flow, corporate finance and take overs', American Economic Review, Vol. 76 No. 2, pp. 323-329.

Karels, G.V. and Sackley, W.H. (1993) 'The relationship between market and accounting betas for commercial banks', Review of Financial Economics, Vol. 2 No. 2, pp. 59-72.

Lapointe, M.-A. (1996) 'Signalisation via dividende et variabilité du flux monétaire', Finéco, Vol. 6 No. 2, pp. 55-70. 
Lintner, J. (1956) 'Distribution of incomes of corporations among dividends, retained earnings, and taxes', American Economic Review, Vol. 76 No. 2, pp. 97-118.

Lucas, R.E. (1978) 'Asset prices in an exchange economy', Econometrica, Vol. 46 No.6, pp. 14291445.

Merton, R.C. (1973) 'An intertemporal capital asset pricing model', Econometrica, Vol. 41 No. 5, pp. 867-887.

Michaely, R., Thaler, R.H. and Womack, K.L. (1995) 'Price reactions to dividend initiations and omissions: overreaction or drift?', The Journal of Finance, Vol. 50 No. 6, pp. 573-608.

Miller, M.H. and Modigliani, F. (1961) 'Dividend policy, growth, and the valuation of shares', Journal of Business, Vol. 34 No. 2, pp. 411-433.

Nekrasov, A. and Shroff, P.K. (2009) 'Fundamentals-based risk measurement in valuation', The Accounting Review, Vol. 84 No. 6, pp. 1983-2011.

Pettit, R.R. (1977) 'Taxes, Transactions Costs and the clientele effect of dividends', Journal of Financial Economics, Vol. 5 No. 3, pp. 419-436.

Rozeff, M.S. (1982) 'Growth, beta and agency costs as determinants of dividend payout ratios', Journal of Financial Research, Vol. 5 No. 3, pp. 249-259.

Rubinstein, M. (1976), 'The valuation of uncertain income streams and the pricing of options', The Bell Journal of Economics, Vol. 7 No. 2, pp. 407-425.

Varela, O. (2015) 'The stock as a portfolio of durations: solving Black's dividend puzzle using Black's criteria', Journal of Portfolio Management, Vol. 41 No. 4 , pp. 122-132.

\section{Notes}

1 Concerning the negative relationship between dividend payout ratio and risk, see, for example, Beaver et al. (1970), Rozeff (1982), and Lapointe (1996). Concerning the negative relationship between dividend yield and risk, see, for example, Pettit (1977), Eades (1982), and Baskin (1989).

2 Generally, an earnings beta (or an accounting beta) represents the covariance between the earnings of a company and the market earnings, divided by the variance of the market earnings.

3 In the present paper, the operators $E_{t}, V A R_{t}$, and $C O V_{t}$ refer respectively to mathematical expectation, variance, and covariance, where index $t$ implies that we consider the available information at time $t$. In addition, the tilde $(\sim)$ indicates a random variable, while $D_{i t}$ represents the current dividends of stock $i$ at time $t$, and $X_{i t}$ represents the current earnings of stock $i$ at time $t$.

4 See, for example, Cochrane (2005, p. 27), Bansal and Kiku (2011), or Bergeron (2013).

5 See Rubinstein (1976) or Cochrane (2005), Chapter 1.

6 If the power utility function is given by: $U(C)=C^{(1-\alpha)} /(1-\alpha)$, then: $U^{\prime}(C)=C^{-\alpha}$, with $\alpha>0$.

7 The operator $E_{t+1}$ refers to mathematical expectation, given the available information at time $t+1$.

8 According to Stein's lemma (Rubinstein, 1976): for random variables $\mathrm{x}$ and $\mathrm{y}$, and for differentiable function $\mathrm{f}(\mathrm{x}) ; \operatorname{COV}[\mathrm{y}, \mathrm{f}(\mathrm{x})]=\mathrm{E}\left[\mathrm{f}^{\prime}(\mathrm{x})\right] \operatorname{COV}[\mathrm{y}, \mathrm{x}]$, if $\mathrm{x}$ and $\mathrm{y}$ are bivariate normally distributed . 
9 By definition, if $X_{1}$ is a random variable, and $X_{0}$ is fixed, then: $G=X_{1} / E\left[X_{1}\right]=X_{0}(1+g) / X_{0} E[1+g]=$ $(1+\mathrm{g}) / \mathrm{E}[1+\mathrm{g}]$, where $\mathrm{g}$ is such that $1+\mathrm{g}=\mathrm{X}_{1} / \mathrm{X}_{0}$.

10 The dividend payout ratio of the S\&P 500 index was never over 75\% between 1960 and 2016.

11 Here, the concept of accounting beta is equivalent to earnings systematic risk.

12 If $G$ and $G_{m}$ are random variables, then: $\operatorname{COV}\left[G, G_{m}\right] / \operatorname{COV}\left[G, G_{m}\right]=1$. 